\title{
The effect of childhood spinal cord injury on skeletal development: a retrospective study
}

\author{
EMK Bergström*, ${ }^{*}$, DJ Short ${ }^{2}$, HL Frankel ${ }^{1}, \mathrm{NJ}_{\text {Henderson }}{ }^{3}$ and PRM Jones ${ }^{4}$ \\ ${ }^{1}$ National Spinal Injuries Centre, Stoke Mandeville Hospital, Bucks, UK; ${ }^{2}$ The Midland Centre for Spinal Injuries, \\ The Robert Jones and Agnes Hunt Hospital, Oswestry, Shropshire, UK, ${ }^{3}$ Department of Trauma and Orthopaedics, \\ Stoke Mandeville Hospital, Aylesbury, Bucks, UK; ${ }^{4}$ Department of Human Science, Loughborough University, \\ Loughborough, Leicestershire, UK
}

\begin{abstract}
Study design: Cross-sectional clinical review.
Objectives: To assess the relationship between late spinal deformity in childhood onset spinal cord injury (SCI) and level of spinal cord lesion, severity of lesion, age at onset, duration of paralysis and pelvic deformities.

Setting: People with spinal cord injury (onset in childhood) treated and followed up at the National Spinal Injuries Center (identified from case notes review, contacted and agreed to participate).

Method: One hundred and eighty-nine subjects satisfying study inclusion criteria (acute onset SCI before the 16th birthday) were identified by case note review of 8200 records. Eighty formed the group attending for clinical review including whole spine radiographs (AP and lateral). Clinical examination included neurological status and joint range of movements. Demographic data was recorded.

Results: Scoliosis occurred more frequently and was more severe in those injured at a younger age, $38^{\circ}$, compared with $24^{\circ}$ in those injured later $(P<0.05)$, in paraplegia, $33^{\circ}$, versus tetraplegia, $17^{\circ},(P<0.01)$ and in complete, $36^{\circ}$, versus incomplete lesions, $18^{\circ},(P<0.001)$. Lordosis angulation in paraplegic subjects was significantly greater than in tetraplegic subjects in both seated, $50^{\circ}$ versus $25^{\circ}(P<0.014)$ and standing subjects $78^{\circ}$ versus $59^{\circ}(P<0.017)$ respectively and for kyphosis in standing subjects, 52 versus $31^{\circ} \quad(P<0.01)$. Sagittal measurements were influenced by habitual posture (which also corresponded to the severity of the lesion).

Conclusion: Younger age at onset was shown to be associated with more severe scoliosis, as has been reported by others. Subjects with paraplegia and complete lesions demonstrated a greater and more frequently occurring scoliosis than those with tetraplegia and incomplete lesions respectively. Lordosis was greater in those with paraplegia than with tetraplegia and in those with very incomplete lesions compared with complete lesions. However the influence of the severity of the lesion cannot be separated from the postural position when analyzing spinal deformity.
\end{abstract}

Keywords: spinal cord injury; child; spinal deformity; scoliosis; kyphosis; lordosis

\section{Introduction}

The number of people sustaining a spinal cord injury (SCI) during childhood is fortunately a small proportion of the SCI population ${ }^{1,2}$ but, as a result, experience in managing spinal cord injured children is relatively limited. Integrating published information is difficult as publications tend to reflect institutional practice bias and selection.

*Correspondence: EMK Bergström, National Spinal Injuries Centre, Stoke Mandeville Hospital, Mandeville Road, Aylesbury, Bucks, HP21 8AL, UK
Developmental issues across the psychologicalphysical spectrum are important in children. Clinical concern has focused on the effects on paralysis on growth, particularly in the development of spinal deformity. ${ }^{3}$

Considerable effort by clinicians, therapists, parents and the children themselves can be put into the prevention of spinal deformity, maintaining upright posture and ambulation with orthoses. Evaluation of the effectiveness of this onerous regimen as well as comparison with other strategies is difficult. 
At the same time as comprehensive prospective monitoring of children with SCI was initiated at the National Spinal Injuries Centre (NSIC), a clinical review was undertaken to learn from the experience, spanning over four decades, of people with childhood onset spinal paralysis. This provided a review of the physical status of this group of people after they had reached adulthood, and in some cases, having had paralysis for many years.

The aim was to examine which factors were relevant to the development of spinal deformity after childhood onset SCI.

Analysis of deformity at the fracture site in those patients in this study who had fractures or fracture/ dislocation in the thoracic or lumbar spine is described elsewhere. ${ }^{4}$

\section{Subjects and method}

\section{Subjects}

The study inclusion criteria were: acute onset of spinal cord lesion, either traumatic or non-traumatic, before the 16th birthday and admission to the National Spinal Injuries Centre (NSIC), Stoke Mandeville Hospital within 1 year of onset.

Excluded were those with conditions predisposing to deformity of the spine or joints, such as idiopathic scoliosis, tuberculosis of the spine and spina bifida. Poliomyelitis was also excluded due to its distinct neurological characteristics.

All of the case notes (8200) at the NSIC between 1945-1989 were examined. Six hundred and seventy seven suffered the onset of paralysis before their 16th birthday. Of these, 38 had polio, 112 had spina bifida, 26 had tuberculosis of the spine and 312 had either other excluding diagnoses (slow onset), were late attenders, or resided overseas (and therefore did not attend regular follow up visits) and were thus excluded from the study.

One hundred and eighty-nine $(2.3 \%$ of the total number of new admissions) fulfilled the study criteria. Of those 23 had died. The remaining 166 were contacted by letter and invited to attend the NSIC for follow up examination and to participate in the study. Eleven replied that they could not or did not wish to participate in the study and 75 did not reply. It can be assumed that many were lost to follow up, as notes spanning 45 years were used. Eighty answered, agreeing to participate, and formed the study group.

All subjects had the full procedure of the clinical review explained in a letter prior to the study and their written consent was obtained. Approval for the study was given by the Aylesbury Vale Health Authority Ethics Committee.

\footnotetext{
Data recorded

Demographic data Age at injury; duration of injury; aetiology; sex.
}

Neurological status Neurological level described as the most caudal segment of the spinal cord with normal sensory and motor function according to the American Spinal Injuries Association (ASIA)/International Medical Society of Paraplegia (IMSOP) scoring system. ${ }^{5}$ Severity of spinal cord lesion as demonstrated by Frankel Grade. ${ }^{6}$ Type of fracture and surgical management.

Skeletal status Scoliosis was assessed by measuring the Cobb angle ${ }^{7}$ taken from antero-posterior (AP) long radiographs of the spinal column. The long radiographs of the spinal column always included the thoracic and lumbar spine and whenever possible the cervical spine. The AP radiograph was taken to include the first sacral vertebra or both iliac crests and the lateral radiograph included the sacrum in order to determine the position of the pelvis.

The radiograph was taken with the subject in their habitual erect posture, either sitting or standing. The erect position was chosen to demonstrate the spine when the gravitational effect was maximal.

Kyphosis and lordosis, were measured in an analogous manner from the lateral radiograph.

Rotation of the most rotated vertebra was measured as the displacement of the pedicles in relation to the edge of the vertebra on an AP radiograph according to Pedriolle. ${ }^{8}$

Pelvic obliquity was measured as the angle between the line connecting the two iliac crests and the edge of the radiograph. To verify that the horizontal corresponded with the edge of the radiograph, the angle between the edge of the radiograph and the line of the air/fluid interface in the stomach was measured. This was visible in 40 radiographs: in 22 this angle was $0^{\circ}$, in twelve $1^{\circ}$, in five $2^{\circ}$ and in one $3^{\circ}$.

Pelvic tilt was measured as the angle between the posterior aspect of the first sacral vertebra and the vertical line.

Range of movement Hip movement was measured in the supine position using a long-armed goniometer in accordance with American Academy of Orthopaedic Surgeons. ${ }^{9}$

\section{Data analysis}

The neurological level of lesion and severity of lesion as well as age at onset, duration of paralysis and aetiology were each divided into two groups for the purpose of description and statistical analysis. This recoding and the analysis was carried out using the SPSS computer package. ${ }^{10}$

The variables describing the subjects neurologically and demographically together with the two way subdivisions of these variables are presented below:

(a) level of lesion: tetraplegia/paraplegia

(b) severity of lesion: complete lesion/incomplete lesion (Frankel Grade A versus B, C, D and E unless otherwise stated) 
(c) age at onset of injury (years): $<11 \mid \geqslant 11$ (to broadly separate pre-adolescent subjects from those already adolescent)

(d) duration (years): $<20 / \geqslant 20$ (because the distribution curve of the numbers of years since injury was normal (mean $19.5, \mathrm{SD} \pm 8.4$, median 19.9)

(e) aetiology: trauma/non-trauma

(f) gender: male/female

The data distribution was assessed from normal distribution plots and parametric statistics employed when homogeneity was shown. Data were analyzed descriptively and results presented as mean $\pm \mathrm{SD}$, cross-tabulation and chi-square. Further analysis of data used $t$-test and analysis of variance. Probability values of $P<0.05$ were taken to be significant.

\section{Results}

\section{Demographic and neurological characteristics of the} sample

The 80 subjects comprised 43 males and 37 females. The mean age was 31.9 years (range: $17.2-50.8$ ) and the mean duration of paralysis was 19.5 years (range: $4.3-37.1)$.

Using chi-square no significant difference $(P<0.05)$ between the 80 study subjects and the remaining 109 cases who were not available for examination with respect to demographic and neurological data was demonstrated.

The distribution of subdivisions previously outlined for the study group is shown in Table 1. Crosstabulation of the 2 way variable subdivisions demonstrated some significant disproportions. There is a significantly larger number of paraplegics among the complete lesions and those injured before age 11 $(P<0.05)$. Among those injured for more than 20 years there is a significant under representation of tetraplegics $(P<0.05)$. Those who suffered a non traumatic lesion tended to be paraplegic and have incomplete lesions $(P<0.05)$.

\section{Aetiology, type of fracture and surgical management} Of 60 traumatic injuries, one resulted from a gunshot wound, eight were classified as spinal cord injury without radiological abnormality (SCIWORA) from their original radiographs and the remainder as fracture dislocation (24), burst fracture (12), wedge fracture (11) and uni or bi-facetal dislocation (3). (One case had no radiographic data from the initial injury time).

Twenty subjects had a non traumatic origin to their spinal cord lesion. The majority of these were paraplegic. Two with diagnosis of spinal cord cyst underwent laminectomy.

Surgery was performed on 15 at the time of injury. In three subjects, the instrumentation was later removed.
Table 1 The distribution of 80 childhood SCI subjects by level of lesion, severity of lesion, age at onset, duration of injury, aetiology and sex

\begin{tabular}{|c|c|c|c|c|c|c|c|c|c|}
\hline & & Tet & Par & $\mathrm{Com}$ & $\begin{array}{l}\text { In } \\
\text { com }\end{array}$ & $\mid<11 \geq 11$ & $\mid<20 \geq 20$ & $\mid \begin{array}{ll}\text { Non } \\
\text { Tr }\end{array}$ & M \\
\hline $\begin{array}{l}\text { Level } \\
\text { of } \\
\text { lesion }\end{array}$ & Tet & 27 & $\frac{}{50}$ & & & & & & \\
\hline Franke & Com & 10 & 34 & 44 & & & & & \\
\hline Grade & Incom & 17 & 19 & & 36 & & & & \\
\hline & $<11$ & & 16 & 13 & $\mid 6$ & 19 & & & \\
\hline onset & $\geq 11$ & 24 & * 37 & 31 & 30 & 61 & & & \\
\hline $\begin{array}{l}\mathrm{Du}- \\
\text { ra- }\end{array}$ & $<20$ & 19 & 22 & 21 & 20 & \begin{tabular}{l|l}
9 & 32 \\
\end{tabular} & 41 & & \\
\hline tion & $\geq 20$ & & 31 & & 16 & \begin{tabular}{l|l}
10 & 29
\end{tabular} & 39 & & \\
\hline $\begin{array}{l}\mathrm{Ae}- \\
\text { tio- }\end{array}$ & $T r$ & 24 & 36 & 37 & 23 & \begin{tabular}{l|l}
13 & 47 \\
\end{tabular} & \begin{tabular}{l|l|}
33 & 27 \\
\end{tabular} & 60 & \\
\hline $\log y$ & Nontr & & 17 & & 13 & \begin{tabular}{l|l}
6 & 14
\end{tabular} & \begin{tabular}{l|l}
8 & 12
\end{tabular} & 20 & \\
\hline \multirow{2}{*}{ Sex } & M & 14 & & & $\mid 17$ & $13 \mid 30$ & $21 \mid 22$ & \begin{tabular}{l|l}
36 & 7
\end{tabular} & 43 \\
\hline & $F$ & 13 & & & $\mid 19$ & $6 / 31$ & \begin{tabular}{l|l}
20 & 17
\end{tabular} & \begin{tabular}{l|l|l}
24 & 13
\end{tabular} & 37 \\
\hline
\end{tabular}

$* P<0.05 ; \quad * * P<0.01 ; \quad * * * P<0.001 ; \quad$ Tet $=$ Tetraplegia, Par $=$ Paraplegia, $\quad$ Com $=$ Complete lesion, In$\mathrm{com}=$ Incomplete lesion, $\operatorname{Tr}=$ Traumatic injury, Nontr $=$ Nontraumatic injury, $\mathrm{F}=$ Female and $\mathrm{M}=$ Male

At the time of this study, two subjects (SCIWORA T10 complete and fracture/dislocation T5 complete) had undergone surgery for scoliosis. Neither of these had surgery at the time of injury. Since the completion of this study surgery has been performed on two more subjects, one with fracture/dislocation T6 complete for scoliosis and the other with spinal fusion of the L4/5 fracture/dislocation.

\section{Missing data}

In three subjects no kyphotic measurements were obtainable due to the poor quality of the radiograph (eg shoulder girdle obscuring the upper thoracic vertebrae), two had pelvic obliquity and one pelvic tilt data missing.

\section{Spinal deformity}

Long spinal radiographs were not taken of the two scoliosis surgery cases and two others (one pregnant and one who did not wish to be subjected to $\mathrm{X}$ radiation). The data analyzed were taken from radiographs of the remaining 76 cases in their habitual erect posture; 22 taken in the standing position (Frankel D) and 54 seated in the wheelchair (Frankel A, B and C). There were no Frankel grade E subjects. 
Spinal deformity was analyzed in its separate components of scoliosis (major curve), lordosis and kyphosis. Only one subject had no deformity in any direction.

Initial analysis of the measurement of rotation in this group showed high correlation $(r=0.89 \mathrm{SEE} \pm$ $6.53^{\circ}$ ) between rotation and scoliosis (Cobb angle). The regression equation obtained for rotation and Cobb angle was: Rotation $^{\circ}=0.4951$ (Cobb angle, $\left.{ }^{\circ}\right)$ -0.0082 .

Due to this close relationship between scoliosis and rotation, it was considered unnecessary to analyze the rotational element of the deformity separately.

Scoliosis ranged from $0^{\circ}-125^{\circ}$. Seventeen of the subjects $(22 \%)$ had a curvature less than $10^{\circ}$, which was classified as no scoliosis. Figure 1 displays the distribution of scoliosis by $10^{\circ}$ intervals in the sitting and standing groups respectively. Sixty-six per cent of

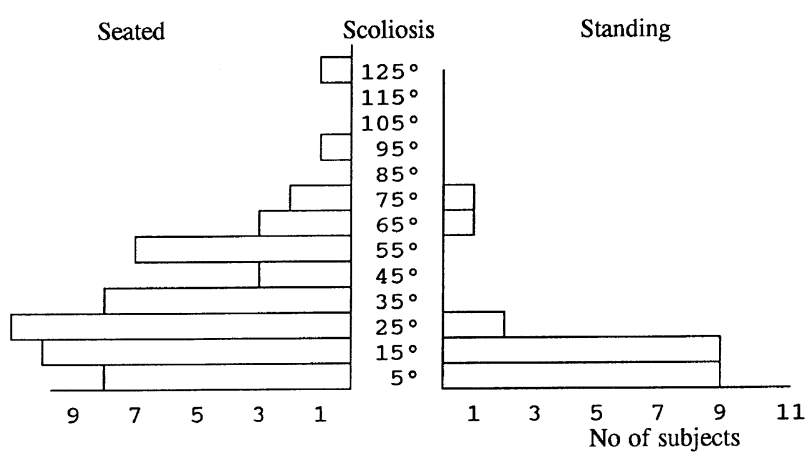

Figure 1 The distribution of scoliosis angle by $10^{\circ}$ interval in 54 seated and 22 standing childhood SCI subjects the seated and $18 \%$ of the standing subjects had a scoliosis of $20^{\circ}$ or more.

Scoliosis was initially analyzed for the group as a whole because the sitting or standing position was felt to have minimal influence in the normal spine on the magnitude of the curve. Table 2 shows the mean scoliosis for the whole group when subdivided by level and severity of lesion, age at onset, duration and hip flexion contracture. The cases with paraplegia and complete lesions, had a significantly greater $(P<0.01)$ scoliosis than their respective counterparts, as had those injured before age 11 and with hip flexion contracture more than $15^{\circ}(P<0.05)$. The duration of injury had no significant influence on the scoliosis angulation or on its distribution.

Spinal deformity data were also analyzed with subjects subdivided into three groups according to Frankel grade (A, B/C, and D). This also divided the sample according to position, as all the subjects with Frankel grade $\mathrm{D}$ in this study were standing. The lordosis, kyphosis and pelvic position were therefore included in this analysis. Table 3 shows the mean angle of each of the variables (together with the $95 \%$ confidence intervals for the mean) in the three Frankel grade groupings. Analysis of variance, performed to ascertain the difference between these three groups, showed that subjects with relatively preserved neurology and whose habitual posture was standing, were different in terms of deformity. Their scoliosis angle was significantly smaller $(P<0.05)$ than in those who had a complete lesion. The mean lordotic angle was significantly larger $(P<0.05)$ in Frankel D (and above normal). ${ }^{11,12}$ The hip flexion contracture and pelvic obliquity was minimal $\left(2^{\circ}\right)$ and

Table 2 The severity of scoliosis expressed as mean Cobb angle and as the frequency of cases with mild, moderate and severe scoliosis by level of injury, severity of injury, age at onset, duration of injury and range of hip movement in 76 SCI subjects

Mean Cobb angle Level of sig.

Number

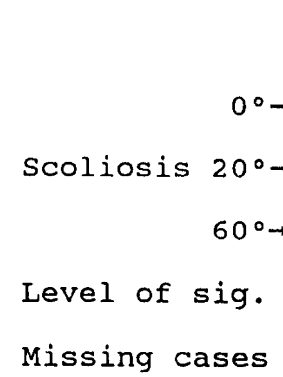

\begin{tabular}{|c|c|c|c|c|c|c|c|c|c|}
\hline \multicolumn{2}{|c|}{ Tet Par } & \multicolumn{2}{|c|}{ com $\begin{array}{l}\text { In- } \\
\text { com }\end{array}$} & \multicolumn{2}{|c|}{$\begin{array}{c}\text { Onset age } \\
<11 \geq 11\end{array}$} & \multicolumn{2}{|c|}{$\begin{array}{l}\text { Duration } \\
<20 \geq 20\end{array}$} & \multicolumn{2}{|c|}{$\begin{array}{l}\text { Flex cont } \\
<15^{\circ} \geq 15^{\circ}\end{array}$} \\
\hline \multicolumn{2}{|c|}{$\begin{array}{c}17^{\circ} \mid 33^{\circ} \\
* *\end{array}$} & \multicolumn{2}{|c|}{$\begin{array}{c}36^{\circ} \mid 18^{\circ} \\
* * *\end{array}$} & \multicolumn{2}{|c|}{$\left.38^{\circ}\right|_{*} ^{2} 24^{\circ}$} & \multicolumn{2}{|c|}{$22^{\circ} \mid 33^{\circ}$} & $\begin{array}{r}21^{\circ} \\
*\end{array}$ & $\begin{array}{l}37^{\circ} \\
*\end{array}$ \\
\hline \multicolumn{2}{|c|}{\begin{tabular}{r|l}
26 & 50 \\
$100 \%$ & $100 \%$
\end{tabular}} & $\begin{array}{r}42 \\
100 \%\end{array}$ & $\begin{array}{l}34 \\
100 \%\end{array}$ & $\begin{array}{r}17 \\
100 \%\end{array}$ & $\begin{array}{l}\mid 59 \\
100 \%\end{array}$ & $\begin{array}{r}38 \\
100 \%\end{array}$ & $\begin{array}{l}38 \\
100 \%\end{array}$ & $\begin{array}{r}42 \mid \\
100 \%\end{array}$ & $\begin{array}{l}32 \\
100 \%\end{array}$ \\
\hline \multicolumn{2}{|c|}{$\left.69\right|^{\frac{\circ}{3}} 36$} & \multicolumn{2}{|c|}{$\left.29\right|^{\circ} 71$} & \multicolumn{2}{|c|}{$\left.24\right|^{\frac{\%}{0}} 54$} & \multicolumn{2}{|c|}{$\left.53\right|^{\circ} 42$} & 59 & 28 \\
\hline 31 & 46 & 55 & 23 & 47 & 39 & 42 & 40 & 36 & 50 \\
\hline 0 & 18 & 16 & 6 & 29 & 7 & 5 & 18 & 5 & 22 \\
\hline \multirow[t]{2}{*}{ * } & $*$ & * & * & & * & & & & * \\
\hline & & & & & & & & \multicolumn{2}{|c|}{2} \\
\hline
\end{tabular}

\footnotetext{
$* P<0.05 ; * * P<0.01 ; * * * P<0.001 ;$ Tet $=$ Tetraplegia, Par $=$ Paraplegia, Com $=$ Complete lesion, Incom $=$ Incomplete lesion
} 
their pelvic anterior tilt significantly larger $(P<0.05)$ than in those seated.

The accumulative influences of level of lesion (tetraplegia and paraplegia) and severity of lesion (complete and incomplete) on the mean scoliosis angle was examined by calculating the mean scoliosis angle for (a) complete tetraplegia $\left(26^{\circ}\right)$, (b) complete paraplegia $\left(38^{\circ}\right)$, (c) incomplete tetraplegia $\left(11^{\circ}\right)$ and incomplete paraplegia $\left(24^{\circ}\right)$. Analysis of variance showed no significant interaction between the effects of level and severity of lesion on the scoliosis angle.

Figure 2 displays the distribution of the lordosis angle by $10^{\circ}$ intervals for the seated and standing subjects. This demonstrates a large proportion of the seated subjects being hypo-lordotic. The difference in the sagittal curvature in the seated and standing position is further illustrated by the location and length of the lordosis and kyphosis. In Figure 3 the most caudal vertebra of the kyphosis in standing and seated subjects respectively is shown, indicating the kyphosis lordosis junction. In the seated subjects the kyphosis is extended into the lumbar spine, five subjects having no lumbar curve at all except between L5 and the sacrum.

To eliminate the confounding influence of level of lesion and posture on scoliosis, lordosis, kyphosis, hip flexion contracture, pelvic obliquity and pelvic tilt, the standing and seated subjects were analyzed separately and each group subdivided into tetraplegic and paraplegic subjects. Student's $t$-tests were performed to evaluate the differences between these two groups. Among the seated subjects the mean lordosis, hip flexion contracture and pelvic tilt was significantly smaller $(P<0.05)$ in tetraplegics compared to paraplegics. The tetraplegics had a flattened lordosis, a mild hip flexion contracture and a posteriorly tilted pelvis (ie 'sacral sitters'). Among the standing subjects, paraplegics had a significantly greater $(P<0.05)$ mean lordosis and kyphosis angle (and greater than normal) ${ }^{11,12}$ than tetraplegics (Table 4).

The length of the scoliotic, lordotic and kyphotic curves are shown in Table 5 for tetraplegics and paraplegics when subdivided by Frankel grade. In the tetraplegic group those with a Frankel grade D have significantly shorter $(P<0.05)$ scoliosis and kyphosis and longer lordosis when compared to those with complete lesions. The lordotic curve was also significantly longer $(P<0.05)$ when comparing those with a Frankel grade D to those with a grade B and C. No significant difference was found in the length of deformity curves between the paraplegic sub groups A, $\mathrm{B} / \mathrm{C}$ and $\mathrm{D}$.

The accumulative impact of level of lesion (para and tetraplegia) and severity of lesion (complete and incomplete) on the length of scoliosis was examined

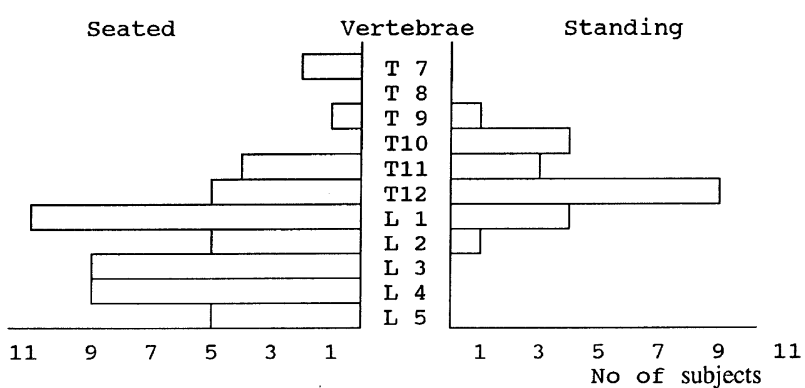

Figure 3 Lowest vertebra of the kyphosis in 22 standing and 51 seated childhood SCI subjects
Figure 2 The distribution of lordosis angle by $10^{\circ}$ interval in 39 seated and 15 standing paraplegic childhood SCI subjects

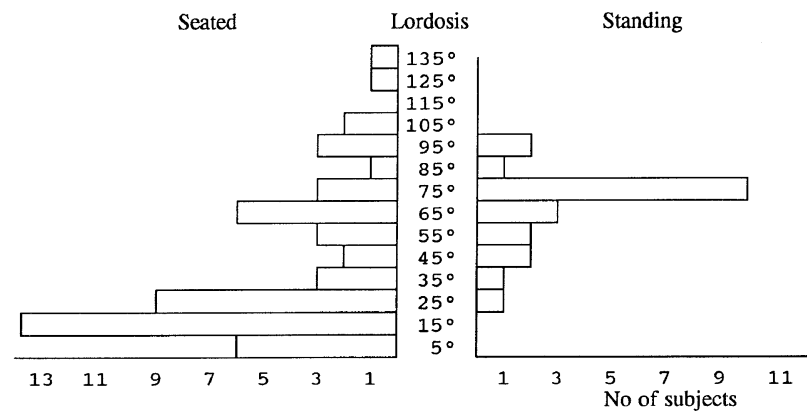

Table 3 The mean angle (and 95\% confidence interval for mean) of deformity (scoliosis, lordosis, kyphosis, hip flexion contracture pelvic obliquity and pelvic tilt) for 76 childhood SCI subjects divided according to Frankel grade

\begin{tabular}{|c|c|c|c|c|c|c|c|}
\hline $\begin{array}{l}\text { Frankel } \\
\text { grade }\end{array}$ & No & Scoliosis & Lordosis & Kyphosis & $\begin{array}{l}\text { Hip flex } \\
\text { contract. }\end{array}$ & $\begin{array}{l}\text { Pelvic } \\
\text { obliquity }\end{array}$ & $\begin{array}{l}\text { Pelvic } \\
\text { tilt }\end{array}$ \\
\hline A (1) & 42 & $\begin{array}{c}36^{\circ} \\
\left(27^{\circ}-44^{\circ}\right)\end{array}$ & $\begin{array}{c}41^{\circ} \\
\left(31^{\circ}-50^{\circ}\right)\end{array}$ & $\begin{array}{r}49^{\circ} \# \# \\
\left(41^{\circ}-56^{\circ}\right)\end{array}$ & $\begin{array}{c}20^{\circ} \\
\left(26^{\circ}-14^{\circ}\right)\end{array}$ & $\begin{array}{c}9^{\circ} \# \\
\left(6^{\circ}-12^{\circ}\right)\end{array}$ & $\begin{array}{c}17^{\circ} \\
\left(10^{\circ}-24^{\circ}\right)\end{array}$ \\
\hline $\mathrm{B} / \mathrm{C}(2)$ & 12 & $\begin{array}{c}23.8^{\circ} \\
\left(10.3^{\circ}-37.4^{\circ}\right)\end{array}$ & $\begin{array}{c}52^{\circ} \\
\left(24^{\circ}-81^{\circ}\right)\end{array}$ & $\begin{array}{c}59^{\circ} \\
\left(41^{\circ}-78^{\circ}\right)\end{array}$ & $\begin{array}{c}26^{\circ} \\
\left(47^{\circ}-5^{\circ}\right)\end{array}$ & $\begin{array}{c}8^{\circ} \# \\
\left(4^{\circ}-12^{\circ}\right)\end{array}$ & $\begin{array}{c}20^{\circ} \# \\
\left(-2^{\circ}-42^{\circ}\right)\end{array}$ \\
\hline D (3) & 22 & $\begin{array}{c}14^{\circ} \\
\left(6^{\circ}-23^{\circ}\right)\end{array}$ & $\begin{array}{c}69^{\circ} \\
\left(60^{\circ}-77^{\circ}\right)\end{array}$ & $\begin{array}{c}43^{\circ} \\
\left(34^{\circ}-51^{\circ}\right)\end{array}$ & $\left(4^{\circ}-0^{\circ}\right)$ & $\begin{array}{c}2^{\circ} \\
\left(0^{\circ}-3^{\circ}\right)\end{array}$ & $\begin{array}{c}51^{\circ} \\
\left(46^{\circ}-56^{\circ}\right)\end{array}$ \\
\hline $\begin{array}{l}\text { Significant difference } \\
\text { between groups }\end{array}$ & & 1 and 3 & 1 and 3 & none & $\begin{array}{l}1 \text { and } 3 \\
2 \text { and } 3\end{array}$ & 1 and 3 & $\begin{array}{l}1 \text { and } 3 \\
2 \text { and } 3\end{array}$ \\
\hline
\end{tabular}


Table 4 The mean angle (and 95\% confidence interval for mean) of scoliosis, lordosis, kyphosis, hip flexion contracture, pelvic tilt and pelvic obliquity for 54 seated and 22 standing childhood SCI subjects divided according to tetraplegia and paraplegia

\begin{tabular}{|c|c|c|c|c|c|c|c|}
\hline $\begin{array}{l}\text { Neuro } \\
\text { level }\end{array}$ & No & Scoliosis & Lordosis & Kyphosis & $\begin{array}{l}\text { Hip flex } \\
\text { contract. }\end{array}$ & $\begin{array}{l}\text { Pelvic } \\
\text { obliquity }\end{array}$ & $\begin{array}{l}\text { Pelvic } \\
\text { tilt }\end{array}$ \\
\hline $\begin{array}{l}\text { Tetraplegia } \\
\quad \text { (seated) }\end{array}$ & 15 & $\begin{array}{c}24^{\circ} \\
\left(15.3^{\circ}-33.3^{\circ}\right)\end{array}$ & $\begin{array}{c}25^{\circ} \\
\left(12.5^{\circ}-38.0^{\circ}\right)\end{array}$ & $\begin{array}{c}49^{\circ} \\
\left(32.2^{\circ}-65.8^{\circ}\right)\end{array}$ & $\begin{array}{c}7^{\circ} \\
\left(1.5^{\circ}-11.9^{\circ}\right)\end{array}$ & $\begin{array}{c}7^{\circ} \# \\
\left(3.4^{\circ}-10.0^{\circ}\right)\end{array}$ & $\begin{array}{c}0^{\circ} \# \\
\left(-10.4^{\circ}-10.3^{\circ}\right)\end{array}$ \\
\hline $\begin{array}{l}\text { Paraplegia } \\
\text { (seated) }\end{array}$ & 39 & $\begin{array}{c}36^{\circ} \\
\left(27.2^{\circ}-45.4^{\circ}\right)\end{array}$ & $\begin{array}{c}50^{\circ} \\
\left(38.2^{\circ}-61.5^{\circ}\right)\end{array}$ & $\begin{array}{c}52^{\circ} \# \# \# \\
\left(43.5^{\circ}-59.7^{\circ}\right)\end{array}$ & $\begin{array}{c}27^{\circ} \\
\left(19.1^{\circ}-30.7^{\circ}\right)\end{array}$ & $\begin{array}{c}10^{\circ} \# \\
\left(5.9^{\circ}-13.1^{\circ}\right)\end{array}$ & $\begin{array}{c}24^{\circ} \\
\left(16.0^{\circ}-31.6^{\circ}\right)\end{array}$ \\
\hline $\begin{array}{l}\text { Significant difference } \\
\text { between groups }\end{array}$ & & $\mathrm{ns}$ & $P<0.017$ & $\mathrm{~ns}$ & $P<0.003$ & $\mathrm{~ns}$ & $P<0.001$ \\
\hline $\begin{array}{l}\text { Tetraplegia } \\
\text { (standing) }\end{array}$ & 11 & $\begin{array}{c}6^{\circ} \\
\left(1.4^{\circ}-11.0^{\circ}\right)\end{array}$ & $\begin{array}{c}59^{\circ} \\
\left(46.6^{\circ}-71.8^{\circ}\right)\end{array}$ & $\begin{array}{c}31^{\circ} \\
\left(23.8^{\circ}-41.6^{\circ}\right)\end{array}$ & $\begin{array}{c}0^{\circ} \\
\left(0^{\circ}-0^{\circ}\right)\end{array}$ & $\begin{array}{c}0^{\circ} \\
\left(-0.2^{\circ}-0.6^{\circ}\right)\end{array}$ & $\begin{array}{c}47^{\circ} \\
\left(38.1^{\circ}-55.1\right)\end{array}$ \\
\hline $\begin{array}{l}\text { Paraplegia } \\
\text { (standing) }\end{array}$ & 11 & $\begin{array}{c}23^{\circ} \\
\left(5.8^{\circ}-39.4^{\circ}\right)\end{array}$ & $\begin{array}{c}78^{\circ} \\
\left(69.1^{\circ}-86.9^{\circ}\right)\end{array}$ & $\begin{array}{c}52^{\circ} \\
\left(40.0^{\circ}-64.3^{\circ}\right)\end{array}$ & $\left(8.3^{\circ}--0.1^{\circ}\right)$ & $\begin{array}{c}3^{\circ} \\
\left(0.0^{\circ}-6.5^{\circ}\right)\end{array}$ & $\begin{array}{c}55^{\circ} \\
\left(48.6^{\circ}-61.0^{\circ}\right)\end{array}$ \\
\hline $\begin{array}{l}\text { Significant difference } \\
\text { between groups }\end{array}$ & & $\mathrm{ns}$ & $P<0.014$ & $P<0.010$ & - & $\mathrm{ns}$ & ns \\
\hline
\end{tabular}

\#missing case

Table 5 The mean numbers of vertebrae in curve (and $95 \%$ confidence interval for mean) of deformity (scoliosis, lordosis, and kyphosis) for 26 tetraplegic and 50 paraplegic childhood SCI subjects divided according to Frankel grade

\begin{tabular}{|c|c|c|c|c|}
\hline $\begin{array}{l}\text { Frankel } \\
\text { grade }\end{array}$ & No & Scoliosis & $\begin{array}{c}\text { Tetraplegia } \\
\text { Lordosis }\end{array}$ & Kyphosis \\
\hline A (1) & 10 & $\begin{array}{c}9.1 \\
(5.9-12.3)\end{array}$ & $\begin{array}{c}3.9 \\
(1.9-5.9)\end{array}$ & $\begin{array}{c}11.4 \\
(9.2-13.7)\end{array}$ \\
\hline $\mathrm{B} / \mathrm{C}(2)$ & 5 & $\begin{array}{c}5.6 \\
(2.2-9.0)\end{array}$ & $\begin{array}{c}3.8 \\
(2.2-5.4)\end{array}$ & $\begin{array}{l}11.8 \\
(9.6-14.0)\end{array}$ \\
\hline D (3) & 11 & $\begin{array}{c}3.5 \\
(1.4-5.7)\end{array}$ & $\begin{array}{c}6.6 \\
(5.7-7.6)\end{array}$ & $\begin{array}{c}8.5 \\
(7.5-9.6)\end{array}$ \\
\hline \multirow{2}{*}{$\begin{array}{l}\text { Significant } \\
\text { difference } \\
\text { between } \\
\text { groups }\end{array}$} & & 1 and 3 & $\begin{array}{l}1 \text { and } 3 \\
2 \text { and } 3\end{array}$ & 1 and 3 \\
\hline & & & Paraplegia & \\
\hline A (1) & 32 & $\begin{array}{c}6.0 \\
(5.1-7.0)\end{array}$ & $\begin{array}{c}4.0 \\
(3.6-4.9)\end{array}$ & $\begin{array}{c}9.6 \# \# \# \\
(8.3-11.0)\end{array}$ \\
\hline $\mathrm{B} / \mathrm{C}(2)$ & 7 & $\begin{array}{c}6.0 \\
(2.3-9.7)\end{array}$ & $\begin{array}{c}6.7 \\
(2.2-11.7)\end{array}$ & $\begin{array}{c}9.0 \# \\
(5.9-12.9)\end{array}$ \\
\hline D (3) & 11 & $\begin{array}{c}5.6 \\
(3.0-8.0)\end{array}$ & $\begin{array}{c}6.2 \\
(5.5-6.9)\end{array}$ & $\begin{array}{c}8.4 \\
(7.2-9.5)\end{array}$ \\
\hline $\begin{array}{l}\text { Significant } \\
\text { difference } \\
\text { between } \\
\text { groups }\end{array}$ & & $\mathrm{ns}$ & $\mathrm{ns}$ & $\mathrm{ns}$ \\
\hline
\end{tabular}

Level of significance $P<0.05$. \#Missing case

by calculating the mean number of vertebrae for (a) complete tetraplegia (9.1) (b) complete paraplegia (6.0) (c) incomplete tetraplegia (4.2) (d) incomplete paraplegia (5.8). Analysis of variance showed a significant interaction $(P<0.005)$ between the level and severity of lesion.

The relationship between the direction of the major scoliosis curve and the pelvic obliquity was investigated. The seated and standing subjects were analyzed separately. Of the 52 seated subjects, 32 had a major scoliosis curve (convex side) and a pelvic obliquity (side down) in the same direction and ten in the opposing direction. The 32 with same sided scoliosis and pelvic obliquity had a compensatory curve above the major curve whereas the ten subjects with opposing direction scoliosis and pelvic tilt had the secondary curve below the major curve. One case had no scoliosis but a pelvic obliquity and two cases had a scoliosis with a level pelvis. The remaining seven had no deformity. Among the 22 standing subjects, five had scoliosis and pelvic obliquity in the same and two in the opposing direction, and six subjects had a scoliosis with a level pelvis. The remaining nine had no deformity.

\section{Discussion}

Study group

The group of 80 adults reviewed in this study are essentially comparable with published series of patients sustaining childhood spinal paralysis. ${ }^{1,13}$ The era of initial treatment and the long time scale of retrospective selection may have influenced some of the characteristics, and largely accounts for the response rate $(42 \%)$ from those we attempted to contact. The proportion of subjects with tetraplegia and incomplete lesions is less than in some recent reports ${ }^{1,14,15}$ but this study shares with many previous publications on childhood onset SCI the potential confounding association of younger age at injury with paraplegia and paraplegia with complete lesions. ${ }^{16-18}$

\section{Scoliosis}

(a) Consistent with previous clinical and radiological assessments, this study found that more severe scoliosis related to younger age at onset of paralysis. ${ }^{16,18,19,20-23}$ 


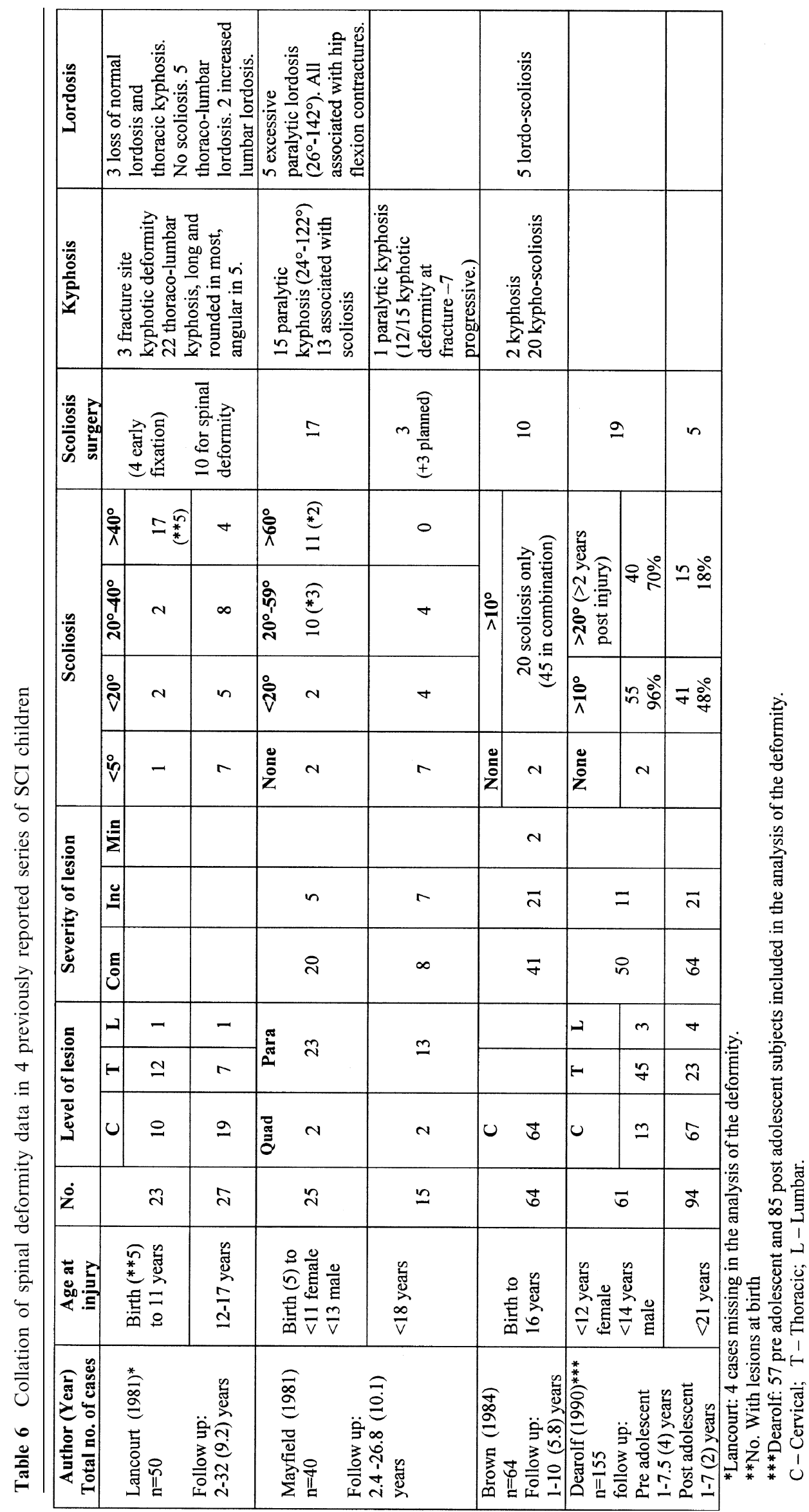


(b) Twenty two per cent (17) of this group had no $\left(<10^{\circ}\right)$ scoliosis. Scoliosis angulation of $20^{\circ}$ or more was seen in $66 \%$ of seated and $18 \%$ of standing subjects.

(c) Scoliosis angle was greater in our paraplegic $\left(33^{\circ}\right)$ versus tetraplegic subjects $\left(17^{\circ}\right)$, comparison within the whole group being statistically significant, similar to findings of Banniza and Paeslack ${ }^{24}$ of severe scoliosis affecting a larger proportion of subjects with thoracic versus cervical lesions. However this is in contrast with the impression generated previously in some studies, of more deformity with higher lesions ${ }^{23}$ and several studies reporting no difference between spinal levels. ${ }^{16,18}$

Scoliosis difference between complete $\left(36^{\circ}\right)$ and incomplete $\left(18^{\circ}\right)$ lesions cannot be separated from their habitual posture (and position radiographed). Analyzing our results, both level and severity influenced scoliosis angulation independently.

(d) Curve lengths (mean number of vertebrae) were similar for complete (6.0) and incomplete (5.8) paraplegics, significantly longer in complete tetraplegic subjects (9.1) and shorter for incomplete tetraplegic subjects with mild angulation (4.2). A strong interaction was found between the level and severity of lesion on the curve length.

\section{Hip flexion contracture}

Hip flexion contracture was significantly related to the degree of scoliosis for all 76 subjects analyzed together. Lancourt et $a l^{16}$ commented that five of their cases with severe scoliosis had dislocated hips. Hip subluxation and the potential for dislocation in spinal cord injured children is also considered to be strongly related to age at onset of paralysis amongst other factors. ${ }^{25}$

\section{Pelvic obliquity}

Pelvic obliquity was measured in 74 subjects. In $68 \%$ obliquity was present (mean $9.8^{\circ}$, range $1^{\circ}-47^{\circ}$ ). Brown et $a l^{22}$ documented pelvic obliquity in $60 \%$ of their patients with scoliosis (mean $8^{\circ}$, range $2^{\circ}-30^{\circ}$ ).

\section{Scoliosis/obliquity side}

Convexity of the scoliosis curve generally coincided with downward displacement of the pelvis on the same side, as expected empirically. Nearly $25 \%$ of our group had the opposite combination with, on closer examination of our data, a compensatory curve below (as opposed to above) the major curve in all these subjects.

\section{Kyphosis/lordosis}

A severe hyper lordosis was present in a number of paraplegic subjects. Two paraplegic subjects had laminectomies performed at onset of paralysis. Both laminectomy sites collapsed into $104^{\circ}$ and $80^{\circ}$ kyphosis with a resultant compensatory lordosis of $110^{\circ}$ and $124^{\circ}$ respectively, representing the second and third greatest lordosis angulation in this study.

In the 22 radiographed standing, kypho-lordotic angulation was relatively accentuated in paraplegic and attenuated in tetraplegic subjects producing definitely hyperlordotic and hypokyphotic measurements respectively, compared to normal. ${ }^{11,12}$

In seated subjects the level of the distal vertebra of the kyphotic curve was lower than normal consistent with the long $\mathrm{C}$ kyphosis (typically in tetraplegics) or conversely, reversal of the sagittal curves with kyphosis in the low thoracic and upper lumbar spine and a flat upper thoracic spine. In our 54 subjects lordotic angulation differs remarkably $(P<0.01)$ between tetraplegics (mean of $25^{\circ}$ ) and paraplegics (mean $50^{\circ}$ ) and, in a clinically related manner, hip flexion contracture and pelvic tilt also differ significantly. There is almost complete distinction between tetraplegics with posteriorly tilted pelves and reduced (and shortened) lumbar lordosis, and paraplegics with less posteriorly tilted pelves, clinically relevant levels of hip flexion contractures and widely varying lordotic angles.

It must be pointed out that all patients with Frankel grade $\mathrm{D}$ were radiographed in standing (their habitual posture) so that any differences between this and other subgroups arising from the severity of the lesion cannot be separated from their habitual posture.

\section{Deformity mechanisms: gravitational collapse/ neuromuscular deformation/habitual posture}

Where the whole thoraco lumbar spine below the level of the SCI is paralysed the gravitational collapse will bring down the whole spine. This is typically seen in the tetraplegic and results in a long and moderate scoliosis. The same thing occurs below the level of the lesion in the paraplegic. In some subjects uneven neuromuscular pull around the level of the lesion may influence the bend in a direct way. In addition, the neurologically intact area above the paralysis will strive for correction of the bend close to its origin resulting in typically shorter and more severe scoliosis in the paraplegic. This is consistent with the findings of Banniza and Paeslack ${ }^{24}$ who suggested that the paralysis itself is the most important factor and Roaf $^{26}$ who suggests uneven neuromuscular pull is the main deforming mechanism.

The wide variation between individuals radiographed in different positions (greater deformity in seated compared with standing subjects) suggests that habitual posture is also relevant in the development of the spinal deformity. As the standing subjects by definition are incomplete it is difficult to establish which has the greater influence, the incompleteness or the position.

The suggestion resulting from these considerations is that maintaining a habitual posture comparable with the sagittal alignment of lumbar spine and pelvis in standing may reduce the overall spinal deformity. It was shown in normal subjects that seating support can 
achieve lumbar lordosis angulation similar to that measured when standing. ${ }^{12}$ This strategy has implications for physical therapy, orthotics, maintaining assisted functional standing and seated support and might offer therapeutic potential.

\section{Scoliosis management}

In terms of management, scoliosis surgery can be more definitively documented than orthotic prescription, usage and especially efficacy. Up to the time of this study the number of people with childhood onset spinal paralysis from our institution who underwent spinal surgery for progressive paralytic deformity was two of 80 . This is relatively small in comparison to those reported in other studies. (See Table 6 for the numbers reported in other studies).

Potentially relevant factors include the era of treatment, national and institutional attitudes toward surgery and the patient population studied. This group contains fewer pre-school age children than the studies listed for comparison. As a result both the prevalence of severe deformity and the indications to interfere surgically are probably very different.

One of the background reasons for undertaking this study was the considerable effort involved in undertaking to prophylactically brace these children, from soon after injury, and strenuously discourage wheelchair use in favour of standing and ambulation with orthoses until no longer practicable. This has been the practice since 1970 but documenting compliance, let alone efficacy retrospectively, was difficult and basically invalid. However, given the suggested role of the habitual posture this management policy should probably be added to the potentially relevant factors influencing the amount of deformity and need for surgery in our study population.

\section{Conclusion}

Younger age at onset was shown to be associated with more severe scoliosis. Duration of injury showed no association with spinal deformity. Subjects with paraplegia and complete lesions demonstrated a greater and more frequently occurring scoliosis than those with tetraplegia and incomplete lesions respectively. The lordotic deformity was greater in subjects with paraplegia than in those with tetraplegia and in subjects with very incomplete lesions compared with complete. The influence of the severity of the lesion cannot be separated from the postural position when analyzing spinal deformity.

\section{References}

1 Vogel LC, De Vivo MJ. Etiology and demographics. In: Betz R and Mulcahey MJ (eds). The child with a spinal cord injury. 1st edn American Academy of Orthopaedic Surgeons: 1996; pp 3-12.
2 Kewalramani LS, Orth MS, Kraus JF, Sterling HM. Acute spinal-cord lesions in a pediatric population: epidemiological and clinical features. Paraplegia 1980; 18: 206-219.

3 Short D, Frankel HL, Bergström EMK. Injuries of the spinal cord in children. In: Vinken PJ, Bruyn GW and Klawans HL (eds) Handbook of clinical Neurology, vol. 61, Frankel HL (coeditor). Spinal cord trauma revised series 17. Elsevier Science Publishers. Amsterdam, London, New York, Tokyo 1992; $232-252$.

4 Bergström EMK et al. The relationship of thoracic and lumbar fracture configuration to the development of late deformity in childhood spinal cord injury. Submitted to Spine May 1999.

5 Maynard Jr FM et al. The international standards booklet for neurological and functional classification of spinal cord injury. Spinal Cord 1994; 32: $70-80$.

6 Frankel HL et al. The value of postural reduction in the initial management of closed injuries to the spine with paraplegia and tetraplegia. Paraplegia 1969; 7: 179-192.

7 Cobb JR. Outline for the study of scoliosis. American Academy of Orthopaedic Surgeons Instructional Course Lectures 1948; 5: $261-275$.

8 Pedriolle R. La scoliose, son étude tridimensionelle. 1979 Paris: Maloine).

9 American Academy of Orthopaedic Surgeons. In: Joint motion; Method of measuring and recording. Churchill Livingstone: Edinburgh London and New York 1965.

10 SPSS PC + for DOS 4.0 [Computer software]. (1990). Chicago, IL: SPSS Inc.

11 Stagnara P. Spinal Deformity. (London: Butterworths) 1988, p. 32.

12 Jackson RP, McManus AC. Radiographic analysis of sagittal plane alignment and balance in standing volunteers and patients with low back pain matched for age sex and size. Spine 1994; 19: $1611-1618$.

13 Young JS, Northup NE. Statistical information pertaining to some of the most commonly asked questions about SCI. National Spinal Cord Injury Data Research Centre 1979.

14 Apple DF, Anson CA, Hunter JD, Bell RB. Spinal cord injury in youth. Clinical Pediatrics 1995; Feb: 90-95.

15 Haffner DL, Hoffer MM. Etiology of children's spinal injuries at Rancho Los Amigos. Spine 1993; 18: 679-684.

16 Lancourt JE, Dickson JH, Carter RE. Paralytic spinal deformity following traumatic spinal-cord injury in children and adolescents. The Journal of Bone and Joint Surgery 1981; 63A: $47-53$.

17 Mayfield JK, Erkkila JC, Winter RB. Spine deformity subsequent to acquired childhood spinal cord injury. The Journal of Bone and Joint Surgery 1981; 63A: $1401-1411$.

18 Dearolf WW et al. Scoliosis in the pediatric spinal cord injured patients. Journal of Pediatric Orthopedics 1990; 10: $214-218$.

19 Burke DC. Traumatic spinal paralysis in children. Paraplegia 1974; 11: $268-276$

20 Campbell J, Bonnett C. Spinal cord injury in children. Clinical Orthopedics and Related Research 1975; 112: 114-123.

21 Andrews LG, Jung SK. Spinal cord injuries in children in British Columbia. Paraplegia 1979; 17: $442-451$.

22 Brown JC, Swank SM, Matta J, Barras DM. Late spinal deformity in quadraplegic children and adolescents. Journal of Pediatric Orthopedics 1984; 4: 456-461.

23 McSweeny T. Spinal deformity after spinal cord injury. Paraplegia 1968; 6: $212-221$.

24 Banniza von Bazan UK, Paeslack V. Scoliotic growth in children with acquired paraplegia. Paraplegia 1977; 15: 65-73.

25 Miller F, Betz R. Hip joint instability. In: Betz R (ed) The child with a spinal cord injury. 1st edn American Academy of Orthopaedic surgeons: 1996, pp 353-361.

26 Roaf R. Scoliosis secondary to paraplegia. Paraplegia 1970; 8: $42-47$. 